\title{
APPLICABILITY OF INTERMITTENT GLOBAL ISCHEMIA FOR REPEAT CORONARY ARTERY OPERATIONS
}

David P. Taggart, MD(Hons), FRCS $^{\mathrm{a}}$

Carlo Atari, $\mathrm{MB}^{\mathrm{a}}$

Poosing Wong, FRCS ${ }^{a}$

Elizabeth A. Paul, BSc, MSc ${ }^{\mathrm{b}}$

John E. Wright, FRCS
Despite the increasing popularity of cardioplegic techniques there is no consensus as to the optimal myocardial protective technique for first-time or repeat coronary artery bypass grafting. Intermittent global ischemia was used in 159 consecutive patients ( 142 male; 17 female) undergoing repeat coronary artery bypass grafting during a 6-year period (1987 to 1992). The median age of the patients was 60 years ( $90 \%$ confidence interval: 47 to 70 years) and the median interval from the first operation was 9 years $(90 \%$ confidence interval: 2 to 14 years). One third of the patients required emergency (within 24 hours) or urgent (within 7 days) operations because of failure of symptoms to resolve with medical therapy. Compared with events at the initial operation there was an increased prevalence of impaired ventricular function (ejection fraction $<50 \%$ ) and increased use of the internal thoracic artery $(48 \%$ versus $9 \%$ ). Two of 12 patients who required emergency operations died in the hospital, which resulted in an overall mortality rate at $\mathbf{3 0}$ days of $1 \%$. Intraaortic balloon pump support was required in five patients $(3 \%)$ and cardiac dose inotropic support in $21 \%$ of patients for up to 24 hours after operation. There was definite electrocardiographic evidence of infarction in 11 patients $(7 \%)$. The mean postoperative blood loss, without aprotinin, was $627 \mathrm{ml}$ (standard deviation $327 \mathrm{ml}$ ) and two patients required reexploration because of bleeding. Five patients had a hemiparesis (3\%) and a further four patients (3\%) had a mild or transient postoperative focal neurologic deficit. The median postoperative hospital stay was 9 days (90\% confidence interval: 7 to 20 days) although $10 \%$ of patients required a hospital stay in excess of 21 days. No patient was lost to follow-up. The median (and interquartile range) period of follow-up was $1.6(1$ to 3 ) years. Eight patients died in the follow-up period, which resulted in an estimated survival of $80 \%$ at 5 years. At a mean follow-up period of 2 years (and with or without antianginal medication) $83 \%$ of patients had no or minimal angina, $12 \%$ had angina on moderate exertion, and 5\% had angina on minimal exertion. In comparison with other current series of repeat coronary revascularization our results suggest that repeat coronary artery bypass grafting can be done with intermittent global ischemia with early and intermediate results at least equivalent to those obtained with cardioplegic methods. (J Thorac Cardiovasc Surg 1996;112:501-7)
From the Department of Cardiac Surgery, ${ }^{\mathrm{a}}$ London Chest Hospital, and the Department of Statistics, ${ }^{b}$ London Hospital Medical College, London, England.

Received for publication June 16, 1995; revisions requested Oct. 5, 1995; revisions received Nov. 2, 1995; accepted for publication Nov. 30, 1995.

Address for reprints: D. P. Taggart, MD(Hons), FRCS, Consultant Cardiothoracic Surgeon, John Radcliffe Hospital, Oxford OX39DU, England.

Copyright (C) 1996 by Mosby-Year Book, Inc.

$0022-5223 / 96 \$ 5.00+0 \quad \mathbf{1 2} / \mathbf{1} / \mathbf{7 1 0 0 7}$
The he requirement for repeat coronary artery bypass grafting $(\mathrm{CABG})$ comprises an ever-increasing proportion of the coronary revascularization workload with the incidence increasing from $3 \%$ at 5 years to $11 \%$ at 10 years and exceeding $17 \%$ at 12 years. ${ }^{1}$ There is no consensus as to the optimal method of myocardial protection for either firsttime or repeat CABG. Commonly used techniques vary from intermittent global ischemia ${ }^{2-5}$ to a plethora of cardioplegic solution compositions, tem- 
Table I. Preoperative risk factors

\begin{tabular}{lc}
\hline & No. $(\%)$ \\
\hline Unstable angina & $57(36)$ \\
Previous myocardial infarction & $102(64)$ \\
$\quad<1 \mathrm{wk}$ & $4(3)$ \\
$1-6 \mathrm{wk}$ & $2(1)$ \\
$>6 \mathrm{wk}$ & $96(60)$ \\
Hypertension (systolic blood pressure & $38(24)$ \\
$\quad>140 \mathrm{~mm} \mathrm{Hg})$ & \\
Hypercholesterolemia & $29(18)$ \\
Diabetes & $23(14)$ \\
Previous cerebrovascular accident & $6(4)$ \\
Morbid obesity (>150\% ideal body weight) & $7(5)$ \\
Current smoker (1-10 cigarettes/day) & $20(13)$
\end{tabular}

peratures, and methods of delivery. ${ }^{6-9}$ Despite the popularity of cardioplegic techniques there are continuing reports of excellent clinical results ${ }^{2,3}$ and low levels of myocardial injury ${ }^{4,5}$ with noncardioplegic techniques. Nevertheless, even proponents of intermittent global ischemia for first-time $\mathrm{CABG}$ advise against its use for repeat $\mathrm{CABG}{ }^{2}$

It is our practice to perform both initial and repeat $C A B G$ with intermittent global ischemia and induced ventricular fibrillation. This paper presents the early and intermediate results with this technique in 159 consecutive patients undergoing repeat CABG during a 6-year period.

\section{Patients and methods}

The case notes of all patients undergoing isolated repeat CABG done by one surgeon (J.E.W.) in this institution during a 6-year period (1987 to 1992) were reviewed. Patients who required concurrent procedures such as a valve operation or aneurysmectomy were not included.

Surgical technique. The surgical technique for repeat operations is similar to that for first-time operations. Both groins are draped but the femoral vessels are not routinely exposed. After median sternotomy and exposure of the aorta, heparin is administered and the distal ascending aorta cannulated. The right atrium is then cannulated with a single atrial basket. Unless there is hemodynamic instability, dissection continues without bypass with every effort being made to minimize handling of previous grafts.

Cardiopulmonary bypass is conducted with nonpulsatile flow and the systemic temperature allowed to drift to $34^{\circ} \mathrm{C}$. No topical cooling is used. There is no routine direct or indirect left ventricular venting. The distal anastomoses are done during brief periods (approximately 10 minutes) of aortic clamping and induced fibrillation. On completion of the distal anastomosis the aortic clamp is released and the proximal anastomosis constructed after a portion of the ascending aorta is isolated in a side-biting clamp. If the heart does not defibrillate spontaneously, defibrillation is achieved with 10 to 20 joules of direct current.
Electrocardiographic diagnosis of myocardial infarction. Serial electrocardiograms (ECGs) were done routinely within 6 hours of the operation and on the first and second postoperative days. Additional ECGs were done as indicated. A new $\mathrm{Q}$ wave ( $>0.04 \mathrm{msec}$ duration) or loss of more than $25 \% \mathrm{R}$ waves in at least two leads was considered diagnostic of infarction. Minor ST-T wave changes and changes in conduction were not by themselves considered diagnostic of infarction.

Follow-up. Review of follow-up outpatient clinic notes and direct contact of the general practitioner was made to determine the following: (1) whether the patient was still alive; (2) whether the patient still had angina and of what severity $(0$, no angina; 1 , angina only on maximum exertion; 2 , angina on moderate exertion; 3 , angina on minimal exertion or at rest or angina that necessitated further hospital admission); and (3) amount of antianginal medication required ( 0 , no medication; 1 , single-drug therapy; 2 , double-drug therapy; 3 , triple-drug therapy) (see appendix).

Statistics. Means and standard deviations are used for data that were normally distributed and medians and $90 \%$ confidence intervals for nonparametric data. Survival data are presented as a Kaplan-Meier survival curve with Greenwood confidence limits (STATA software, version 3.1, sixth edition, Stata Corporation, College Station, Tex.).

\section{Results}

Patients. During a 6-year period (1987 to 1992) 159 consecutive patients underwent repeat CABG done by one surgeon (J.E.W.). The group comprised 142 men and 17 women. The median age of the patients was 60 years (90\% confidence interval: 47 to 70 years) and $5 \%$ of patients were older than 70 years. The median interval from the first operation was 9 years ( $90 \%$ confidence interval: 2 to 14 years).

Follow-up. No patient was lost to follow-up. The median (and interquartile range) period of follow-up was 1.6 ( 1 to 3 ) years.

Preoperative risk factors. Preoperative risk factors are summarized in Table I. Two thirds of patients had previously had a myocardial infarction ( $4 \%$ within the preceeding 6 weeks), one quarter had hypertension, one fifth had hypercholesterolemia, and $14 \%$ had diabetes. Additionally $4 \%$ of patients were morbidly obese ( $>150 \%$ ideal body weight), $4 \%$ had had a previous cerebrovascular accident, and $13 \%$ were current smokers.

Cardiac catheterization. Angiography before the repeat operation invariably showed severe disease or occlusion of previous vein grafts usually accompanied by progression of native coronary artery disease. Almost $70 \%$ of previous grafts were totally occluded and of the remaining patent grafts half were obviously diseased (stenosis $>50 \%$ ). Ventricu- 
Table II. Ventricular function as assessed by EF

\begin{tabular}{lcc}
\hline & \multicolumn{2}{c}{ No. of patients (\%) } \\
\cline { 2 - 3 } & Initial operation & Repeat operation \\
\hline Good $(>50 \%)$ & $119(75)$ & $80(50)$ \\
Fair $(30 \%-49 \%)$ & $32(20)$ & $52(32)$ \\
Poor $(<30 \%)$ & $1(1)$ & $21(13)$ \\
Missing data & $7(4)$ & $7(4)$ \\
\hline
\end{tabular}

lography (Table II) revealed good ventricular function (ejection fraction $[\mathrm{EF}]>50 \%$ ) in $50 \%$ of patients at repeat $\mathrm{CABG}$ compared with $75 \%$ at the initial operation. In contrast $32 \%$ of patients undergoing repeat $\mathrm{CABG}$ had fair (EF $30 \%$ to $49 \%$ ) and $13 \%$ poor ventricular function $(\mathrm{EF}<30 \%$ ) compared, respectively, with $20 \%$ and $1 \%$ at the first operation. Data concerning EF were missing in $4 \%$ of patients.

Symptoms and urgency of operation. Ninetythree patients $(58 \%)$ had stable angina and 57 $(36 \%)$ had unstable symptoms. Every effort was made to stabilize symptoms with maximal medical therapy including intravenous nitrates and heparin. Only those patients in whom this regimen failed to stabilize the symptoms or who could not tolerate withdrawal of intravenous nitrates or heparin underwent operation within 7 days of referral. Only patients with ongoing chest pain, accompanied by hemodynamic instability or ECG changes, or both, underwent emergency operations. Consequently 107 patients $(67 \%)$ underwent elective reoperation, 40 $(25 \%)$ required urgent reoperation (between 1 and 7 days after hospital admission), and 12 patients $(8 \%)$ required an emergency operation (within 24 hours of referral).

Procedures at reoperation (Table III). A mean of 2.6 grafts had been inserted at the initial operation with $9 \%$ of patients receiving an internal thoracic artery (ITA) graft and 18\% requiring an endarterectomy. At repeat operation a mean of 2.4 grafts were inserted with $48 \%$ of patients receiving an ITA graft and $15 \%$ requiring an endarterectomy. At repeat $\mathrm{CABG}$ there was a significant increase in the number of grafts to the circumflex system and an increase in the frequency of grafts to the posterior descending artery rather than the main right coronary artery.

Deaths (Table IV). Two patients died within 30 days of the operation $(1 \%)$. Both were patients who required emergency repeat $\mathrm{CABG}$. One died as a result of low cardiac output in the operating room despite the use of an intraaortic balloon pump and
Table III. Procedure at repeat operation

\begin{tabular}{lcc}
\hline & \multicolumn{2}{c}{ No. of patients (\%) } \\
\cline { 2 - 3 } & Initial operation & Repeat operation \\
\hline Endarterectomy & $29(18)$ & $24(15)$ \\
0 & $130(82)$ & $135(85)$ \\
1 & $25(16)$ & $22(14)$ \\
2 & $4(3)$ & $2(1)$ \\
ITA used & $14(9)$ & $77(48)$ \\
0 SVG & $2(1)$ & $9(6)$ \\
1 SVGs & $17(11)$ & $38(24)$ \\
2 SVGs & $46(29)$ & $76(48)$ \\
3 SVGs & $74(47)$ & $30(19)$ \\
4 SVGs & $17(11)$ & $5(3)$ \\
5 SVGs & $1(1)$ & 0 \\
Missing data & $2(1)$ & $1(1)$ \\
LAD graft & $132(83)$ & $132(83)$ \\
Diagonal graft & $42(26)$ & $19(12)$ \\
Intermediate graft & $3(2)$ & $10(6)$ \\
OM graft & $40(25)$ & $83(52)$ \\
RCA graft & $86(54)$ & $65(41)$ \\
PDA graft & $25(16)$ & $44(28)$ \\
\hline
\end{tabular}

$S V G$, Saphenous vein graft; $L A D$, left anterior descending; $O M$, obtuse marginal; $R C A$, right coronary artery; $P D A$, posterior descending artery.

the other died of intractable ventricular fibrillation. A further eight patients $(5 \%)$ died outside the hospital within the follow-up period, although it was not possible to establish the precise cause of death in the absence of autopsy examination.

Intraaortic balloon pump. An intraaortic balloon pump was required in five patients $(3 \%)$ to assist weaning from cardiopulmonary bypass. Of these patients one died, three required intraaortic balloon pump support for 3 days, and one patient required this support for 1 day.

Ventilation and intensive care unit stay. Extubation was possible in $72 \%$ of patients within 12 hours of return to the intensive care unit (ICU) and in $96 \%$ within 24 hours. Discharge from the ICU was achieved in $79 \%$ of patients within 24 hours, in $92 \%$ within 48 hours, and in $96 \%$ within 72 hours. In $4 \%$ of patients the ICU stay was between 3 and 9 days.

Inotropic support. Renal-dose dopamine $(<5$ $\mu \mathrm{g} / \mathrm{kg}$ per minute) was administered routinely. Cardiac-dose dopamine (5 to $10 \mu \mathrm{g} / \mathrm{kg}$ per minute) was required in $15 \%$ of patients and a further $6 \%$ required epinephrine in the early postoperative period. In most patients inotropic therapy was discontinued within 24 hours but $7 \%$ of patients required inotropic support for up to 5 days.

Bleeding. Aprotinin was not used in any patient. The mean postoperative blood loss was $627 \mathrm{ml}$ (standard deviation $327 \mathrm{ml}$ ). Two patients were 
Table IV. Comparison of patient population and complications with those of other series

\begin{tabular}{|c|c|c|c|c|c|}
\hline Study & Taggant & Lytle $^{12}$ & Salomon $^{13}$ & Rosengart $^{14}$ & $A k l^{15}$ \\
\hline Years of study & $1987-1992$ & $1988-1991$ & $1970-1988$ & 1988-1992 & $1981-1990$ \\
\hline No. of patients & 159 & 1663 & 508 & 240 & 115 \\
\hline $\begin{array}{l}\text { Mean age at initial and repeat } \\
\text { operations (yr) }\end{array}$ & $52 / 60$ & $53 / 63$ & $56 / 60$ & $55 / 64$ & $\mathrm{NR} / 54$ \\
\hline Male patients (\%) & 89 & 85 & 82 & 85 & 95 \\
\hline Interval between operations (yr) & 8.7 & 9.5 & 7.6 & 9.1 & 7.4 \\
\hline Urgent/emergency operations (\%) & 33 & 2 & 3 & 54 & NR \\
\hline Good LV function $(\mathrm{EF}>50 \%)(\%)$ & 51 & 61 & 50 & NR & 75 \\
\hline $\begin{array}{l}\text { Use of ITA, first versus repeat } \\
\text { operation }(\%)\end{array}$ & $9 ; 48$ & $33 ; 61$ & $46 ; 24$ & $15 ; 59$ & $5 ; 63$ \\
\hline Myocardial protection & $\operatorname{IGI}\left(34^{\circ} \mathrm{C}\right)$ & $\mathrm{CC} ; \mathrm{BC} \mathrm{a}, \mathrm{r}$ & NR & $\mathrm{BC} a, \mathrm{r}$ & $\mathrm{IGI} ; \mathrm{CC}$ a \\
\hline Core temp $\left({ }^{\circ} \mathrm{C}\right)$ & 34 & Cold & NR & Cold & 30 \\
\hline Hospital death (\%) & 1 & 4 & 7 & 6 & 5 \\
\hline \multicolumn{6}{|l|}{ Complication $(\%)$} \\
\hline Infarct & 7 & 7 & 9 & NR & 4 \\
\hline Stroke & 4 & 3 & 2 & NR & 4 \\
\hline Bleeding & 1 & 4 & 7 & NR & 3 \\
\hline
\end{tabular}

$N R$, Not recorded; $L V$, left ventricular; $I G I$, intermittent global ischemia; $C C$, crystalloid cardioplegia; $B C$, blood cardioplegia; $a$, antegrade; $r$, retrograde.

returned to the operating room because of surgical bleeding.

Arrhythmias. Atrial fibrillation necessitating digitalization occurred in 22 patients $(14 \%)$ and other supraventricular arrythmias developed in four others (3\%).

Myocardial infarction. There was definite ECG evidence of perioperative infarction in 11 patients $(7 \%)$.

Cerebrovascular accident. Five patients had a hemiparesis $(3 \%)$ and survived with a persisting moderate to severe deficit. Four other patients $(3 \%)$ had minor focal neurologic deficits that resolved completely.

Wound infection. Sternal dehiscence occurred in one patient and superficial wound infections in 13 $(8 \%)$.

Hospital stay. The median hospital stay was 9 days. Seventy-five percent of patients were discharged from the hospital within 12 days and $90 \%$ within 20 days. Nevertheless $10 \%$ of patients required a hospital stay in excess of 3 weeks.

Follow-up (Fig. 1). During the follow-up period of the study eight patients died (in addition to the 2 operative deaths), which resulted in an estimated survival of $82 \%$ (95\% confidence interval: $65 \%$ to $92 \%$ ) at 5 years. At most recent follow-up $59 \%$ of patients were free from angina, 24\% had angina on severe exertion, $12 \%$ had angina on moderate exertion, and $5 \%$ had angina on minimal exertion or at rest. With regard to antianginal medication $32 \%$ of patients required no medication, $21 \%$ required sin- gle-drug therapy, $8 \%$ required two drugs, $9 \%$ required three drugs, and $4 \%$ required four drugs (drug therapy data were missing in 12\%).

\section{Discussion}

Despite its continued use in first-time CABG there has been no report specifically addressing the use of intermittent global ischemia for repeat CABG. Indeed, a recent review of techniques for myocardial protection in repeat $\mathrm{CABG}$ did not mention noncardioplegic techniques, ${ }^{7}$ and even strong proponents of its use in first-time CABG advise against its use in repeat operations. ${ }^{2}$

Our main rationale for the use of intermittent global ischemia for repeat CABG is based on the excellent clinical results ${ }^{2,3}$ and low levels of myocardial injury ${ }^{4,5}$ obtained with its use in first-time CABG. In a randomized trial, with use of the highly specific marker cardiac troponin $\mathrm{T}$ to quantify myocardial injury, we demonstrated that intermittent global ischemia provides at least equivalent myocardial protection to that of antegrade delivery of cold crystalloid cardioplegic solution in first-time CABG. ${ }^{5}$ It is possible that the cardioprotective efficacy of intermittent global ischemia may be a result, at least in part, of "ischemic preconditioning," the phenomenon whereby a brief period of ischemia followed by reperfusion makes the myocardium less vulnerable to subsequent ischemic periods. ${ }^{10}$ Ischemic preconditioning, one of the most powerful and reproducible endogenous methods of myocardial protection, is inducible in all animal 


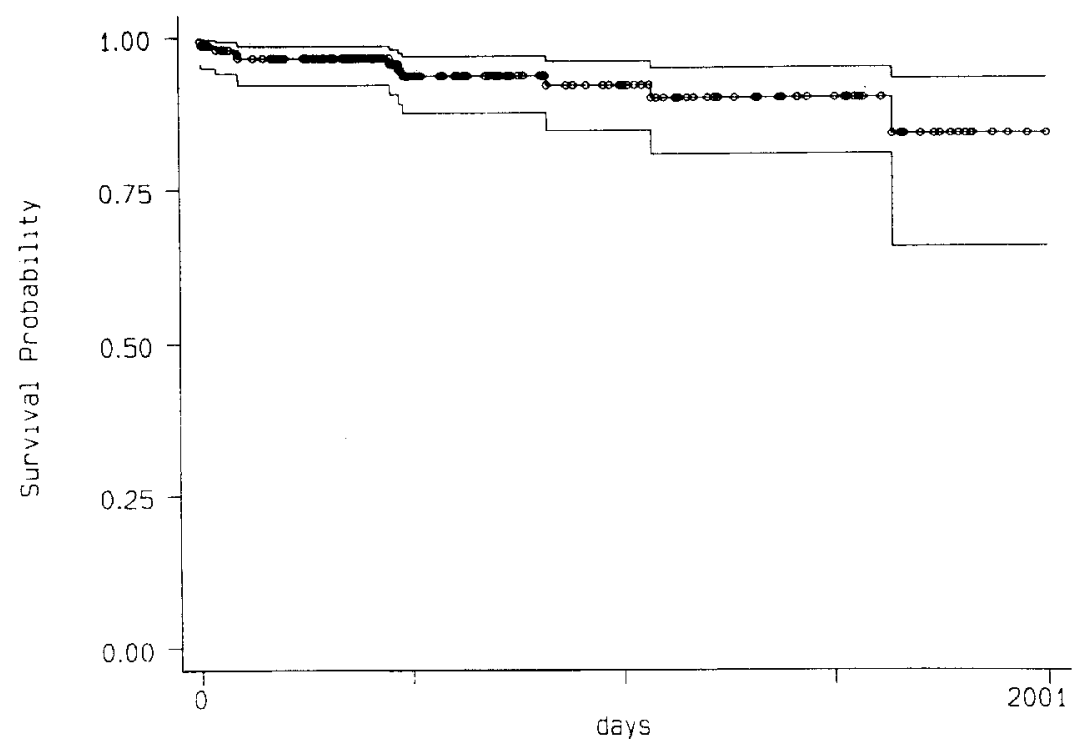

Fig. 1. Kaplan-Meier survival curve with Greenwood confidence limits.

species and has recently been demonstrated in clinical practice. ${ }^{11}$

The major limitation of the current study is that of all retrospective nonrandomized studies of repeat CABG. ${ }^{12-15}$ Nevertheless, the strengths of our study are that it includes all patients who underwent repeat $\mathrm{CABG}$ during a 6-year period in one hospital done by one surgeon and that the clinical end points of death, ECG-confirmed myocardial infarction, and cerebrovascular accident provide suitably hard end points to allow comparison with other studies of repeat $\mathrm{CABG} .{ }^{12-15}$ In terms of age, sex distribution, and interval from the initial operation, our patients are similar to those in other current studies of repeat $\mathrm{CABG}$ (Table IV). ${ }^{12-15}$ Our patients were, however, a mean of 8 years older than those previously undergoing repeat $\mathrm{CABG}$ in this hospital ${ }^{16,17}$ and those reported elsewhere in the United Kingdom. ${ }^{15}$

The overall 30 -day mortality rate of $1 \%$ in our patients is favorable in comparison with that in other reports in the literature (Table IV) and particularly so considering that one third of our patients required urgent or emergency operations (Table IV). The two patients who died in our series were among the 12 patients in the emergency group $(17 \%)$. One major difference among the studies of repeat $\mathrm{CABG}$ is the proportion of patients who required an urgent or emergency operation (Table IV). In the largest and most recent reports from the Cleveland Clinic ${ }^{12}$ and the Oregon group, ${ }^{13}$ fewer than $3 \%$ of patients undergoing repeat $\mathrm{CABG}$ required emergency or urgent operations in contrast to $33 \%$ of our patients and $54 \%$ of those reported by Rosengart and colleagues. ${ }^{14}$ This presumably reflects differences in referral patterns to different institutions rather than variance in medical management, inasmuch as our policy was to strenuously avoid reoperation in the acute situation. Only those patients whose symptoms could not be controlled with maximal medical therapy or who could not tolerate withdrawal of intravenous nitrates or heparin underwent operation within 7 days of referral. Emergency operations were reserved for patients with ongoing chest pain, accompanied by hemodynamic instability or ECG changes or both despite full medication.

As with all techniques for repeat $C A B G$ the presence of patent but diseased vein grafts merits special consideration. In our population almost $70 \%$ of previous grafts were totally occluded and of the remainder approximately half had obvious disease. This is similar to the experience of the Harefield group. ${ }^{15}$ Retrograde cardioplegia has been advocated as the preferred technique for myocardial protection for repeat $\mathrm{CABG}$ because of its theoretic potential for reducing distal embolization from diseased grafts and improving delivery of cardioplegic solution beyond stenosed or occluded grafts. Claims that retrograde cardioplegia improves the results of repeat operations have, however, been largely based on results of nonrandomized historically controlled 
studies. ${ }^{7-9}$ The prevalence of ECG-confirmed perioperative myocardial infarction of $7 \%$ in our study is similar to that in other studies of repeat CABG (Table IV) and even in studies by the advocates of retrograde cardioplegia. ${ }^{7-9}$ Indeed, the similarity of perioperative infarction rates in our study and in those in which retrograde cardioplegia was used suggests that perioperative infarction might be largely caused by dislodgement of debris from diseased but patent grafts before the institution of cardiopulmonary bypass.

Of particular relevance in the preoperative risk factors was the deterioration in left ventricular function in patients having repeat CABG. The proportion of our patients with good left ventricular function $(\mathrm{EF}>50 \%)$ decreased from $75 \%$ at the initial operation to $50 \%$ at repeat operation, similar to that reported in other studies (Table IV). Simultaneously, the proportion of our patients with poor left ventricular function $(\mathrm{EF}<30 \%)$ increased from $1 \%$ at the initial operation to $12 \%$ at repeat operation.

The most significant difference between initial and repeat operations in our patients was the increased use of the ITA from $9 \%$ to $48 \%$, respectively. Lack of use of the ITA during first-time CABG is now recognized to be one of the risk factors for necessitating repeat $\mathrm{CABG} .{ }^{1}$ In our study only $48 \%$ of patients undergoing repeat $\mathrm{CABG}$ received an ITA graft, which is similar to the frequency of its use (between $46 \%$ and $63 \%$ ) in other studies of repeat CABG. ${ }^{12-15}$ The relatively low use of the ITA in our patients undergoing repeat $C A B G$ was for two reasons: (1) ITA grafts were not widely used in the United Kingdom until their associated benefits were firmly established by the Cleveland Clinic in $1986^{18}$ and (2) there were concerns about the suitability of the ITA in the one third of patients who required urgent or emergency repeat $\mathrm{CABG}$. The presence of a patent ITA graft at repeat operation was uncommon in our study but did not interfere with the technique of intermittent global ischemia. In such situations careful dissection of the ITA from the surface of the heart allowed application of a soft bulldog clamp, if necessary, during the period of ischemia. As reported in the other studies of repeat $\mathrm{CABG}$, the total number of grafts inserted at reoperation tends to be less than that in the initial operation. ${ }^{12-15}$

One major concern with intermittent global ischemia is the possibility of an increased risk of cerebrovascular accident because of the requirement for repeated clamping of the aorta during the distal anastomosis and isolation of a portion of ascending aorta in a side-biting clamp for construction of the proximal anastomosis. Five (3\%) of our patients had a hemiparesis, a prevalence similar to that reported in other series of repeat $C A B G$ with a variety of cardioplegic techniques (Table IV). A further four patients had transient or mild focal neurologic deficits, ${ }^{19}$ which resolved completely. In one of the largest studies to date, Martin and colleagues ${ }^{20}$ reported a prevalence of perioperative stroke at $3 \%$ (and total neurologic events at $4.5 \%$ ) in 493 patients undergoing first-time $\mathrm{CABG}$ and randomized to receive warm blood cardioplegic solution administered in combined antegrade and retrograde fashion.

There are few data in the literature regarding the durations of postoperative ventilation, ICU and hospital stay, and, consequently, financial implications for repeat CABG. Even without aprotinin therapy the mean postoperative blood loss was $627 \mathrm{ml}$ (standard deviation $327 \mathrm{ml}$ ) and only two patients required reexploration because of bleeding. In our study $96 \%$ of patients were extubated within 24 hours of the operation and $92 \%$ were discharged from the ICU within 48 hours. Nevertheless, $3 \%$ of patients required intraaortic balloon pump support, approximately one fifth required cardiac-dose inotropic therapy, and $4 \%$ of patients required an ICU stay of between 3 and 9 days. The median hospital stay in our patients was 9 days compared with an average of 11 days in New York Hospital, ${ }^{21}$ but $10 \%$ of our patients required a hospital stay in excess of 3 weeks.

In the follow-up period there were eight deaths among our patients, which gave an estimated 5-year survival of approximately $80 \%$. Even after repeat operation the most important influence on longevity is ventricular function and our 5-year survival is similar to that reported by Salomon and colleagues ${ }^{13}$ for patients with an EF of $41 \%$ to $60 \%$.

It is estimated that the recurrence of angina after repeat operations is almost double that of the first-time operation. ${ }^{21}$ Lytle and colleagues ${ }^{22}$ reported that $50 \%$ of patients were free from angina 5 years after repeat operations. Although our results compare favorably, because $83 \%$ of patients were free from angina at a mean follow-up period of 4 years, $46 \%$ of patients required between two and four drugs as antianginal medication. However, at a mean follow-up period of 2 years, $12 \%$ of our patients had angina on moderate exertion and $5 \%$ had angina on minimal exertion, which confirms the palliative nature of repeat operations. 
In summary, our results demonstrate that repeat coronary revascularization can be done with intermittent global ischemia with little mortality and acceptable short-term results at least as favorable as those reported with cardioplegic techniques. Whether retrograde cardioplegic techniques, as currently advocated, would lead to a reduction in mortality and morbidity would require a prospective, randomized clinical trial.

\section{REFERENCES}

1. Cosgrove DM, Loop FD, Lytle BW, et al. Predictors of reoperation after myocardial revascularization. J Thorac Cardiovasc Surg 1986;92:811-21.

2. Bonchek LI, Burlingame MW, Vazales BE, Lundy EF, Gasmann CJ. Applicability of noncardioplegic coronary bypass to high-risk patients: selection of patients, technique, and clinical experience in 3000 patients. J Thorac Cardiovasc Surg 1992;103:230-7.

3. Flameng W. Intermittent ischemia. Semin Thorac Cardiovasc Surg 1993;5:107-13.

4. Taggart DP, Young V, Hooper J, et al. Lack of cardioprotective efficacy of allopurinol in coronary artery surgery. $\mathrm{Br}$ Heart J 1994;71:177-81.

5. Taggart DP, Bhusari S, Hooper J, et al. Intermittent ischaemic arrest and cardioplegia in coronary artery surgery: coming full circle? Br Heart J 1994;72:136-9.

6. Buckberg GD. Myocardial protection: an overview. Semin Thorac Cardiovasc Surg 1993;5:98-106.

7. Cohn LH. Myocardial protection for reoperative cardiac surgery in acquired heart disease. Semin Thorac Cardiovasc Surg 1993;5:162-7.

8. Loop FD, Higgins TL, Panda R, Pearce G, Estafanous FG. Myocardial protection during cardiac operations: decreased morbidity and lower cost with blood cardioplegia and coronary sinus perfusion. J Thorac Cardiovasc Surg 1992;104:60818.

9. Gundry SR, Razzouk AJ, Vigesaa RE; Wang N, Bailey LL. Optimal delivery of cardioplegic solutions for "redo" operations. J Thorac Cardiovasc Surg 1992;103:896-901.

10. Murray CE, Jenings RB, Reimer KA. Preconditioning with ischemia: a delay of lethal cell injury in ischemic myocardium. Circulation 1986;74:1124-36.

11. Yellon DM, Alkhulaifi AM, Pugsley WB. Preconditioning the human myocardium. Lancet 1993;342:276-7.

12. Lytle BW, McElroy D, McCarthy $P$, et al. Influence of arterial coronary bypass grafts on the mortality in coronary reoperations. J Thorac Cardiovasc Surg 1994;107:675-83.

13. Salomon NW, Page US, Bigelow JC, Krause AH, Okies JE, Metzdorff MT. Reoperative coronary surgery: comparative analysis of 6591 patients undergoing primary bypass and 508 patients undergoing reoperative coronary artery bypass. J Thorac Cardiovase Surg 1990;100:250-60.
14. Rosengart TK, Krieger K, Lang SJ, et al. Reoperative coronary artery bypass surgery: improved preservation of myocardial function with retrograde cardioplegia. Circulation 1993;88(pt 2):330-5.

15. Akl ES, Ozdogan E, Ohri SK, et al. Early and long term results of re-operation for coronary artery disease. Br Heart J 1992;68:176-80.

16. Brooks N, Honey M, Cattell M, et al. Reoperation for recurrent angina. $\mathrm{Br}$ Heart J 1979;42:333-8.

17. Pidgeon N, Brooks N, Magee P, Pepper JR, Sturridge MF, Wright JE. Reoperation for angina after previous aortocoronary bypass surgery. Br Heart J 1985;53:269-75.

18. Loop FD, Lytle BW, Cosgrove DM, et al. Influence of the internal manmary artery graft on 10-year survival and other cardiac events. N Engl J Med 1986;314:1-6.

19. Taggart DP, Reece IJ, Wheatley DJ. Cerebral deficit after elective cardiac surgery. Lancet 1987:1:47.

20. Martin TD, Craver JM, Gott JP, et al. Prospective, randomized trial of retrograde warm blood cardioplegia: myocardial benefit and neurologic threat. Ann Thorac Surg 1994;57:298304.

21. Rosengart TK. Risk analysis of primary versus reoperative coronary artery bypass grafting. Ann Thorac Surg 1993;56: S74-7.

22. Lytle BW, Loop FD, Cosgrove DM, et al. Fifteen hundred coronary reoperations. J Thorac Cardiovase Surg 1987;93: $847-59$.

\section{Appendix}

Questionnaire to general practitioner:

Is your patient alive or dead?

If dead, when and how did he/she die?

When did you last see your patient?

Does your patient have angina?

If yes, what is his/her functional class?

1. No limitation of physical activity. Ordinary physical activity does not cause undue fatigue, palpitation, dyspnea, or angina.

2. Slight limitation of physical activity. Comfortable at rest but ordinary physical activity results in fatigue, palpitation, dyspnea, or angina.

3. Marked limitation of physical activity. Comfortable at rest but less than ordinary physical activity causes fatigue, palpitation, dyspnea, or angina.

4. Inability to carry on any physical activity without discomfort. Symptoms of cardiac insufficiency or angina may be present even at rest. If any physical activity is undertaken, discomfort is increased.

Is your patient receiving antianginal medication?

If yes, what is it?

Has the patient had an ECG stress test or a cardiac catheterization since the operation?

If yes, do you know the result? 